\title{
Effects of maternal psychotropic drug dosage on birth outcomes
}

\author{
This article was published in the following Dove Press journal: \\ Neuropsychiatric Disease and Treatment \\ 9 December 2013 \\ Number of times this article has been viewed
}

\author{
Laura A Michielsen' \\ Frank MMA van der \\ Heijden' \\ Paddy KC Janssen ${ }^{2}$ \\ Harold JH Kuijpers' \\ 'Vincent van Gogh Institute for \\ Psychiatry, Venlo, the Netherlands; \\ ${ }^{2}$ Department of Pharmacy, VieCuri \\ Medical Centre, Venlo, \\ the Netherlands
}

Correspondence: Harold JH Kuijpers Twee Steden Ziekenhuis, Dr Deelenlaan 5, 5042 AD Tilburg, the Netherlands Tel +3I I 34655520 Fax +3II 34655556 Email h.kuijpers@tsz.nl
Background: The aim of this retrospective study was to explore the relationship between psychotropic medication dosage and birth outcomes.

Methods: A total of 136 women were enrolled, who had an active mental disorder, were taking medication to prevent a relapse, or had a history of postpartum depression or psychosis. Medication use was evaluated for the three trimesters and during labor. Based on the defined daily dose, medication use was classified into three groups. Primary outcome variables included the infant gestational age at birth, birth weight, and Apgar scores at one and 5 minutes.

Results: Our study showed a significantly higher incidence of Apgar score $\leq 7$ at 5 minutes in women taking psychotropic drugs as compared with the group taking no medication, respectively ( $16.3 \%$ versus $0.0 \%, P=0.01$ ). There was no significant difference between the two groups in Apgar score at one minute or in gestational age and birth weight. The results showed no significant differences in gestational age, birth weight, or Apgar scores for a low-intermediate or high dose of a selective serotonin reuptake inhibitor and for a low or intermediate dose of an antipsychotic.

Conclusion: This study does not indicate a relationship between doses of selective serotonin reuptake inhibitors and antipsychotics and adverse neonatal outcomes.

Keywords: pregnancy, psychotropic medication, dosage, birth outcomes

\section{Introduction}

Mental disorders are common during pregnancy, affecting $15 \%-29 \%$ of all pregnant women. ${ }^{1}$ Treatment of these patients is a special challenge for clinicians, and requires involvement of several specialists for mother and child. A recent study showed that untreated maternal depression was associated with slower rates of fetal growth. ${ }^{2}$ Further, other studies have suggested that untreated maternal depression can have a negative impact on delivery outcomes, infant neuropsychologic development, and social behavior during adolescence. However, the evidence is not conclusive. ${ }^{3,4}$

Although treatment of depression during pregnancy is regarded as necessary, evidence about the safety of pharmacologic treatment is scarce. Selective serotonin reuptake inhibitors (SSRIs) are among the most investigated psychotropic drugs used during pregnancy. There have been numerous studies focusing on the effect of SSRIs on birth outcomes, such as gestational age, birth weight, Apgar scores, admission to neonatal intensive care units, and various malformations. ${ }^{2,5-8}$ The possible adverse effects of prenatal SSRI exposure are not limited to birth outcomes. Recent studies have shown that prenatal SSRI exposure has a negative impact on early neurologic functioning, as reflected by general movement quality and increased hypertonia in 
exposed children. ${ }^{9,10}$ Impaired motor functioning, in turn, has been associated with numerous comorbid conditions, including nocturnal enuresis ${ }^{11}$ and migraine. ${ }^{12}$ Further, SSRI exposure has been associated with mental health problems in children. ${ }^{13,14}$ However, the reported results regarding various types of outcomes have been conflicting. ${ }^{15-17}$ Some studies have investigated other psychotropic drugs, like non-SSRI antidepressants and antipsychotics. For example, a recent cohort study showed an increased risk of gestational diabetes in women taking antipsychotics and of macrocephaly in their children. ${ }^{18}$

Only a few studies have addressed the effect of medication dosage on birth outcomes. ${ }^{19-22}$ Knowledge about the effect of dosage is important to give clinicians guidance in their pharmacologic treatment. The aim of this study was to analyze the relationship between medication dose and birth outcomes.

\section{Materials and methods}

\section{Setting, patients, and study design}

This retrospective study was conducted at the Vincent van Gogh Institute for Psychiatry and VieCuri Medical Centre in Venlo, The Netherlands. All women referred to the multidisciplinary psychiatry and pregnancy team in 2004, 2005, and 2008-2011 were eligible for this study. The multidisciplinary team consisted of a gynecologist, pediatrician, pharmacist, and psychiatrist. The patients either had an active mental disorder, were taking medication to prevent a relapse, or had a history of postpartum depression or psychosis. One patient with a twin pregnancy was excluded, along with 17 further patients in whom no actual pregnancy was registered. In total, 136 patients were enrolled. There was no control group.

All hospital medical records were screened for information about demographic and maternal characteristics like gravidity, intoxications, intention to lactate, and clinical admissions. Ethnic background was divided into three groups based on the definitions of Statistics Netherlands. ${ }^{23}$ Non-Dutch Western persons were from Europe (excluding Turkey), North America, Oceania, Indonesia, or Japan. Women from Africa, Latin America, Asia, and Turkey were classified as non-Dutch non-Western. All psychiatric records were reviewed for mental or personality disorders during pregnancy and before. Information about medication was obtained from prescriptions, charts, and hospital pharmacy records. We classified women as taking medication if they were taking medication at some point during their pregnancy. Medication use was initially classified into three categories based upon the defined daily dose. ${ }^{24}$ A low dose was defined as less than the defined daily dose, an intermediate dose as 1-2 defined daily doses, and a high dose as two or more defined daily doses. Women were classified into groups based on the highest dose taken. In the SSRI group, the low and intermediate categories were combined for analysis of the birth outcome variables. Daily doses were also converted into multiples of the defined daily dose.

\section{Outcomes}

Primary outcome variables included birth weight, gestational age at birth, and Apgar scores at one and 5 minutes. Gestational age was verified by early ultrasound examination. Secondary outcomes were preterm birth, low birth weight, and small for gestational age. Preterm birth was defined as delivery before 37 weeks of gestation. Low birth weight was defined as a birth weight $<2,500 \mathrm{~g}$. Small for gestational age was defined as a standard deviation score below -2 based on Dutch reference curves. $^{25}$

\section{Statistical analysis}

Categoric variables were presented as counts and percentages. Continuous variables were presented as the mean and standard deviation or median and range as appropriate. Fisher's exact test and the Mann-Whitney $U$ test were used for comparisons of the groups. Statistical significance was set on a two-sided $P$-value of $<0.05$. All statistical analyses were performed using IBM Statistical Package for the Social Sciences version 20 software (IBM Corporation, Armonk, NY, USA). Adjusted analyses for low birth weight and preterm birth were not possible due to the low number of cases.

\section{Results}

\section{Characteristics}

In total, 136 women were enrolled in this study. Their mean age was $31.0 \pm 5.22$ (range 18-43) years. Mood disorders $(\mathrm{n}=59 ; 43 \%)$ were the most common mental disorders followed by anxiety disorders $(n=33 ; 24 \%)$, psychotic disorders $(n=14)$, and mild anxiety and mood symptoms $(n=13)$. Twenty-seven percent of our population had a personality disorder $(n=37)$. Not all patients experienced active symptoms during their pregnancy $(n=81 ; 60 \%)$. Medication was used by 98 women $(72 \%)$ at some point during their pregnancy, with highest incidences occurring during the first and third trimester.

\section{Medication}

Overall, the median amount of defined daily dose was 1.0 (range 0.13-3.00). Citalopram was the most com- 
monly used psychotropic drug $(n=29)$. Other SSRIs were paroxetine $(n=13)$, fluvoxamine $(n=11)$, fluoxetine $(n=4)$, escitalopram $(n=3)$, and sertraline $(n=2)$. Non-SSRI antidepressants were venlafaxine $(n=9)$, mirtazapine $(n=6)$, clomipramine $(n=4)$, amitriptyline $(\mathrm{n}=1)$, and bupropion $(\mathrm{n}=1)$. The antipsychotics were haloperidol $(n=9)$, risperidone $(n=5)$, quetiapine $(n=3)$, pipamperon $(n=3)$, olanzapine $(n=2)$, and aripiprazole $(n=1)$. The mood stabilizers were lithium $(n=2)$ and valproic acid $(n=2)$. One valproic acid user stopped using this medication after a positive pregnancy test. Anxiolytics and hypnotics were used by 25 women, and two women used stimulants. Twenty women used concomitant drugs, ie, antiemetics $(n=7)$, antihypertensive drugs $(n=6)$, asthma medication $(n=4)$, levothyroxine $(n=2)$, biperiden $(n=2)$, iron supplements $(n=1)$, insulin $(\mathrm{n}=1)$, and dexamethasone $(\mathrm{n}=1)$.

\section{Infant outcomes}

The infant outcomes compared for women taking or not taking psychotropic medication are listed in Table 1. The incidence of an Apgar score $\leq 7$ at 5 minutes was significantly higher in the medication group $(P=0.01)$. Nevertheless, the median Apgar scores at one and 5 minutes were identical in both groups. In the group without medication, the incidence of preterm birth was $2.7 \%(n=1)$, and was $11.1 \%(n=11)$ in the group with medication; however, this difference was not statistically significant $(P=0.18$, Figure 1). One stillbirth occurred in each group. The woman with a stillbirth in the medication group was taking mirtazapine for her entire pregnancy and oxazepam in the first trimester.
Two thirds of the women taking an SSRI used a lowintermediate dose $(n=42)$. One woman switched from paroxetine to fluoxetine in the first trimester, and all other women used only one type of SSRI. The median gestational age in the women taking SSRIs was 39.1 weeks. The incidence of preterm birth was $9.5 \%(n=4)$ in women taking a low-intermediate dose compared with $21.1 \%$ $(n=4)$ in women taking a high dose; however, the difference was not statistically significant $(P=0.24)$. In the group of women taking a low-intermediate SSRI dose, the median birth weight was 3.47 compared with 3.22 in women taking a high dose. Median Apgar scores at one and 5 minutes were identical in the two groups, ie, 9 and 10 , respectively. Between-group differences in gestational age, birth weight, and Apgar scores did not reach statistically significant levels.

In the group of women taking antipsychotics, no preterm birth, low birth weight, or small for gestational age neonates occurred. The median gestational age (39.7) and Apgar scores at one and 5 minutes were identical ( 9 and 10) in the low-dose and intermediate-dose category. In the intermediate group, the median birth weight was $3.77 \mathrm{~kg}$, and was $3.55 \mathrm{~kg}$ in the low-dose group $(P=0.63)$.

\section{Discussion}

The incidence of an Apgar score $\leq 7$ at 5 minutes was significantly higher in women taking psychotropic drugs at $16.3 \%$ versus $0.0 \%$ in the group taking no medication $(P=0.01)$. There was no significant difference in Apgar score between the two groups at one minute. A possible explanation for these results is that the children in the group taking no medication, who need a little bit more time to start breathing

Table I Birth outcomes for women taking and not taking medication

\begin{tabular}{|c|c|c|c|c|c|c|c|}
\hline & \multicolumn{2}{|c|}{ No medication $(n=37)^{a}$} & \multicolumn{2}{|c|}{ Medication $(n=99)^{b}$} & \multicolumn{2}{|c|}{ Total $(n=136)$} & \multirow[t]{2}{*}{$P$} \\
\hline & $\mathbf{n}$ & $\%$ & $\mathbf{n}$ & $\%$ & $\mathbf{n}$ & $\%$ & \\
\hline Male infant & 14 & 38.9 & 49 & 50.5 & 63 & 47.4 & 0.25 \\
\hline Preterm birth & 1 & 2.7 & 11 & II.I & 12 & 8.8 & 0.18 \\
\hline SGA & 2 & 5.9 & 3 & 3.2 & 5 & 3.9 & 0.61 \\
\hline Low birth weight & I & 2.9 & 7 & 7.4 & 8 & 6.2 & 0.68 \\
\hline Apgar one minute $\leq 5$ & I & 2.9 & 13 & 14.1 & 14 & 11.1 & 0.11 \\
\hline \multirow[t]{2}{*}{ Apgar 5 minutes $\leq 7$} & 0 & 0.0 & 15 & 16.3 & 15 & 11.9 & 0.01 \\
\hline & Median & Range & Median & Range & Median & Range & $P$ \\
\hline Gestational age (weeks) & 39.1 & $26.0-42.0$ & 39.3 & $24.4-42.3$ & 39.1 & $24.4-42.3$ & 0.83 \\
\hline Birth weight $(\mathrm{kg})$ & 3.3 & $2.0-4.2$ & 3.4 & I.2-4.6 & 3.4 & $1.5-4.6$ & 0.30 \\
\hline Apgar score, one minute & 9 & $5-10$ & 9 & $1-10$ & 9 & $1-10$ & 0.13 \\
\hline Apgar score, 5 minutes & 10 & $9-10$ & 10 & $2-10$ & 10 & $2-10$ & 0.52 \\
\hline
\end{tabular}

Notes: a One sex and three birth weights and Apgar scores were missing; ${ }^{b}$ two sexes, four birth weights and seven Apgar scores were missing. Abbreviation: SGA, small for gestational age. 
The incidence of preterm birth

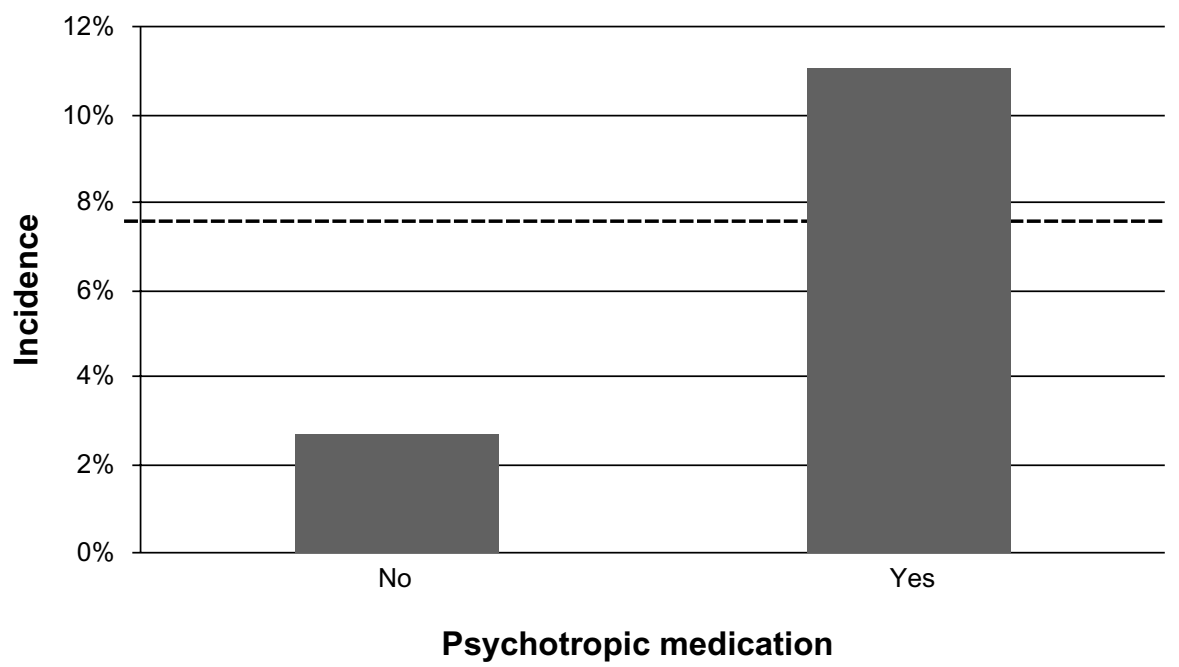

Figure I Incidence of preterm birth for women taking or not taking medication.

Notes: Tracked line indicates population incidence of preterm birth in The Netherlands $(7.7 \%) .{ }^{19}$ The incidence of preterm birth was $2.7 \%$ in the group without medication and $11.1 \%$ in the group with medication $(P=0.18)$.

and moving, have normalized Apgar scores at 5 minutes. Children of mothers who used antenatal psychotropic drugs experience negative effects for a longer time. In line with this possible explanation, the current guideline on SSRI use in pregnancy and lactation from the Dutch Society of Obstetrics and Gynaecology recommends observation of newborns for a period of 3 days due to the risk of impaired neonatal adaptation. ${ }^{26}$ An Apgar score $\leq 7$ at 5 minutes is associated with a higher prevalence of neurologic disability and with low cognitive function in early adulthood. ${ }^{27}$

Further, the results indicate a higher incidence of preterm birth and low birth weight in women taking medication compared with women taking no medication. However, these results were not significant. The overall incidence of preterm birth is $7.7 \%$ in The Netherlands, which is lower than our overall incidence $(8.8 \%)$, the incidence in the psychotropic group (11.1\%), and that in the SSRI group $(13.1 \%) .{ }^{28}$ The same accounts for our overall incidence of low birth weight (8.5\%) and small for gestational age (5.1\%), with population incidences of $4.8 \%$ and $2.3 \%$, respectively. ${ }^{29}$ Our study showed no significant difference in gestational age, birth weight, or Apgar scores for a low-intermediate or high dose of SSRI or for a low or intermediate dose of antipsychotic. However, it should be noted that comparison of our groups is complicated by the heterogenous population, eg, comorbid conditions, smoking, and timing of drug use.

Suri et a $\mathrm{l}^{19}$ found a lower gestational age at birth in women taking a higher dose of antidepressants. They divided women with a history of depression into three groups, ie, no antidepressant use, a low to medium dose, and a high dose. The median gestational age in their high-dose SSRI group was also lower than in the intermediate and low groups. However, between-group differences were not significant. As in our study, birth weight and Apgar scores were not significantly different between the dose groups. Consistent with these results, Roca et $\mathrm{al}^{20}$ found that women treated with SSRIs, mainly at a high dose, had a lower gestational age and increased risk of preterm birth. However, Oberlander et a ${ }^{21}$ found no association between dose and adverse neonatal outcomes. A comparison of the results is limited by the use of different dosage categorizations.

This study has several strengths. First, we classified medication use based on defined daily doses determined by the World Health Organization. Standardization of definitions for dose categories simplifies comparison of different studies. Second, unlike other studies addressing use of antidepressants only, we also evaluated the relationship between antipsychotic dosage and birth outcomes. Finally, this study was conducted in a population with real-life characteristics.

Our study has a few limitations. Because of the retrospective design, it was not possible to obtain exact information about medication use. However, we tried to be as thorough as possible by assessing not only prescriptions and hospital pharmacy records, but also obstetric and psychiatric charts. Giving the low number of concomitant drugs used, there is probably an under-reporting of this usage. Second, our 
outcome variables were not normally distributed. Possible causes for this are low sample sizes and outliers.

The findings of this study indicate no relationship between SSRI and antipsychotic dosage and adverse neonatal outcome. Nevertheless, a possible relationship between dosage and birth outcome cannot be ruled out. Taking the results of previous studies into account, a prospective large-scale study with a control group is necessary. There seems to be a tendency towards a slightly poorer outcome in women taking psychotropic drugs during their pregnancy, especially for Apgar score at 5 minutes. These results indicate a need to observe these children for a longer period of time as compared with children from women taking no medication.

\section{Acknowledgment}

The authors would like to thank EJ Wijnen and RMM Thompson, members of the multidisciplinary psychiatry and pregnancy team, for their support with data collection.

\section{Disclosure}

The authors report no conflicts of interests in this work.

\section{References}

1. Vesga-López O, Blanco C, Keyes K, Olfson M, Grant BF, Hasin DS. Psychiatric disorders in pregnant and postpartum women in the United States. Arch Gen Psychiatry. 2008;65(7):805-815.

2. El Marroun H, Jaddoe VW, Hudziak JJ, et al. Maternal use of selective serotonin reuptake inhibitors, fetal growth, and risk of adverse birth outcomes. Arch Gen Psychiatry. 2012;69(7):706-714.

3. Davalos D, Yadon C, Tregellas H. Untreated prenatal maternal depression and the potential risks to offspring: a review. Arch Womens Ment Health. 2012;15(1):1-14.

4. Gentile S. Drug treatment for mood disorders in pregnancy. Curr Opin Psychiatry. 2011;24(1):34-40.

5. Lund N, Pedersen LH, Henriksen TB. Selective serotonin reuptake inhibitor exposure in utero and pregnancy outcomes. Arch Pediatr Adolesc Med. 2009;163(10):949-954.

6. Hayes RM, Wu P, Shelton RC, et al. Maternal antidepressant use and adverse outcomes: a cohort study of 228,876 pregnancies. Am J Obstet Gynecol. 2012;207(1):49.e1-49.e9.

7. Lewis AJ, Galbally M, Opie G, Buist A. Neonatal growth outcomes at birth and one month postpartum following in utero exposure to antidepressant medication. Aust $N$ Z J Psychiatry. 2010;44(5):482-487.

8. Oberlander TF, Warburton W, Misri S, Aghajanian J, Hertzman C. Neonatal outcomes after prenatal exposure to selective serotonin reuptake inhibitor antidepressants and maternal depression using population-based linked health data. Arch Gen Psychiatry. 2006;63(8):898-906.

9. Croen LA, Grether JK, Yoshida CK, Odouli R, Hendrick V. Antidepressant use during pregnancy and childhood autism spectrum disorders. Arch Gen Psychiatry. 2011;68(11):1104-1112.

10. Salisbury AL, Wisner KL, Pearlstein T, Battle CL, Stroud L, Lester BM. Newborn neurobehavioral patterns are differentially related to prenatal maternal major depressive disorder and serotonin reuptake inhibitor treatment. Depress Anxiety. 2011;28(11):1008-1019.
11. Esposito M, Gallaj B, Parisi L, et al. Visuomotor competencies and primary monosymptomatic nocturnal enuresis in prepubertal aged children. Neuropsychiatr Dis Treat. 2013;9:921-926.

12. Esposito M, Verrotti A, Gimigliano F, et al. Motor coordination impairment and migraine in children: a new comorbidity? Eur J Pediatr. 2012; 171(11):1599-1604.

13. de Vries NK, van der Veere CN, Reijneveld SA, Bos AF. Early neurological outcome of young infants exposed to selective serotonin reuptake inhibitors during pregnancy: results from the observational SMOK study. PLoS One. 2013;8(5):e64654.

14. Rai D, Lee BK, Dalman C, Golding J, Lewis G, Magnusson C. Parental depression, maternal antidepressant use during pregnancy, and risk of autism spectrum disorders: population based case-control study. $B M J$. 2013;346:f2059.

15. Nordeng H, van Gelder MM, Spigset O, Koren G, Einarson A, Eberhard-Gran M. Pregnancy outcome after exposure to antidepressants and the role of maternal depression: results from the Norwegian mother and child cohort study. J Clin Psychopharmacol. 2012;32(2): 186-194.

16. Wisner KL, Bogen DL, Sit D, et al. Does fetal exposure to SSRIs or maternal depression impact infant growth? Am J Psychiatry. 2013;170(5):485-493.

17. Gentile S, Galbally M. Prenatal exposure to antidepressant medications and neurodevelopmental outcomes: a systematic review. J Affect Disord. 2011;128(1-2):1-9.

18. Boden R, Lundgren M, Brandt L, Reutfors J, Kieler H. Antipsychotics during pregnancy: relation to fetal and maternal metabolic effects. Arch Gen Psychiatry. 2012;69(7):715-721.

19. Suri R, Altshuler L, Hellemann G, Burt VK, Aquino A, Mintz J. Effects of antenatal depression and antidepressant treatment on gestational age at birth and risk of preterm birth. Am J Psychiatry. 2007;164(8): 1206-1213.

20. Roca A, Garcia-Esteve L, Imaz ML, et al. Obstetrical and neonatal outcomes after prenatal exposure to selective serotonin reuptake inhibitors: the relevance of dose. J Affect Disord. 2011;135(1-3): 208-215.

21. Oberlander TF, Warburton W, Misri S, Aghajanian J, Hertzman C. Effects of timing and duration of gestational exposure to serotonin reuptake inhibitor antidepressants: population-based study. Br J Psychiatry. 2008;192(5):338-343.

22. Berard A, Ramos E, Rey E, Blais L, St-Andre M, Oraichi D. First trimester exposure to paroxetine and risk of cardiac malformations in infants: The importance of dosage. Birth Defects Res B Dev Reprod Toxicol. 2007;80(1):18-27.

23. Statistics Netherlands. Annual report on integration 2008. Available from: http://www.cbs.nl. Updated 2008. Accessed July 16, 2012.

24. WHO Collaborating Centre for Drug Statistics. ATC/DDD index 2012 Available from: http://www.whocc.no/atc_ddd_index/. Updated 2011. Accessed June 20, 2012.

25. Visser GH, Eilers PH, Elferink-Stinkens PM, Merkus HM, Wit JM. New Dutch reference curves for birthweight by gestational age. Early Hum Dev. 2009;85(12):737-744.

26. Dutch Society of Obstetrics and Gynaecology. SSRI-gebruik in de zwangerschap en tijdens de lactatie [Guideline for SSRI use in pregnancy and lactation]. Available from: http://nvog-documenten.nl/index. php?pagina=/richtlijn/pagina.php\&fSelectTG_62=75\&fSelectedSub=62 \&fSelectedParent=75. Updated 2012. Accessed January 8, 2013. Dutch.

27. Ehrenstein V, Pedersen L, Grijota M, Nielsen GL, Rothman KJ, Sørensen HT. Association of Apgar score at five minutes with long-term neurologic disability and cognitive function in a prevalence study of Danish conscripts. BMC Pregnancy Childbirth. 2009;9:14.

28. Waelput AJM. Hoe vaak komt vroeggeboorte voor en hoeveel kinderen sterven eraan? [The incidence of preterm birth and the related mortality rate]. Available from: http://www.nationaalkompas.nl. Updated 2011. Accessed July 19, 2012. Dutch.

29. Dutch statistics. Perinatale en zuigelingensterfte eenlingkinderen; geboortegewicht. [Perinatal and infant mortality in singleton children; birthweight] Available from: http://statline.cbs.nl/StatWeb/publication/?DM=SLNL\&P $\mathrm{A}=80215 \mathrm{NED} \& \mathrm{D} 1=0-2,4-5,7,18-19,21-22 \& \mathrm{D} 2=\mathrm{a} \& \mathrm{D} 3=0,3,1 \& \mathrm{HDR}=\mathrm{T}$ $\& \mathrm{STB}=\mathrm{G} 2, \mathrm{G} 1 \& \mathrm{VW}=\mathrm{T}$. Updated 2011. Accessed July 19, 2012. Dutch. 


\section{Publish your work in this journal}

Neuropsychiatric Disease and Treatment is an international, peerreviewed journal of clinical therapeutics and pharmacology focusing on concise rapid reporting of clinical or pre-clinical studies on a range of neuropsychiatric and neurological disorders. This journal is indexed on PubMed Central, the 'PsycINFO' database and CAS.

The manuscript management system is completely online and includes a very quick and fair peer-review system, which is all easy to use. Visit http://www.dovepress.com/testimonials.php to read real quotes from published authors.

\footnotetext{
Submit your manuscript here: http://www.dovepress.com/neuropsychiatric-disease-and-treatment-journal
} 